\title{
Do pharmacy practice standards effectively describe behaviour? Reviewing practice standards using a behavioural specificity framework
}

Deanna Mill ${ }^{1 *}$, Amy Page ${ }^{1,2,3}$, Jacinta Johnson ${ }^{4,5}$, Kenneth Lee' ${ }^{1}$, Sandra M. Salter ${ }^{1}$, Liza Seubert ${ }^{1}$, Rhonda Clifford ${ }^{1}$ and Danielle D'Lima ${ }^{6}$

\begin{abstract}
Background: Guidelines and practice standards exist to communicate the conduct and behaviour expected of health care professionals and ensure consistent quality practice. It is important that they describe behaviours explicitly so they can be interpreted, enacted and measured with ease. The AACTT framework specifies behaviour in terms of the: Action to be performed, Actor who performs the action, Context where the action occurs, Target who the action is performed with/for and Time when the action is performed (AACTT). It provides the most up to date framework for specifying behaviours and is particularly relevant to complex behavioural problems that involve sequences of behaviours performed by different people. Behavioural specificity within pharmacy practice standards has not been explored.
\end{abstract}

Aim: To determine if behaviours described in the Professional Practice Standards for Australian Pharmacists specify Action, Actor, Context, Target and Time.

Methods: Two researchers independently reviewed the scope and structure of the practice standards and one extracted action statements (behaviours) verbatim. Through an iterative process, the researchers modified and developed the existing AACTT definitions to operationalise them for application to review of the action statements in the practice standards. The operational definitions, decision criteria and curated examples were combined in a codebook. The definitions were consistently applied through a directed content analysis approach to evaluate all extracted action statements by one researcher. For consistency $20 \%$ was independently checked for agreement by a second researcher.

Results: A novel codebook to apply AACTT criteria to evaluate practice standards was developed. Application of this codebook identified 768 independent behaviours. Of these, 300 (39\%) described at least one discrete observable action, none specified an actor, 25 (3\%) specified context, 131 (17\%) specified target and 88 (11\%) specified time.

Conclusion(s): The behaviours detailed in practice standards for Australian pharmacists do not consistently specify behaviours in terms of Action, Actor, Context, Target and Time. Developers in the pharmacy profession, and beyond, should consider the behavioural specificity of their documents to improve interpretability, usability and adherence

\footnotetext{
${ }^{*}$ Correspondence: Deanna.Mill@research.uwa.edu.au

1 School of Allied Health, The University of Western Australia, Perth,

Western Australia, Australia

Full list of author information is available at the end of the article
}

(C) The Author(s) 2022. Open Access This article is licensed under a Creative Commons Attribution 4.0 International License, which permits use, sharing, adaptation, distribution and reproduction in any medium or format, as long as you give appropriate credit to the original author(s) and the source, provide a link to the Creative Commons licence, and indicate if changes were made. The images or other third party material in this article are included in the article's Creative Commons licence, unless indicated otherwise in a credit line to the material. If material is not included in the article's Creative Commons licence and your intended use is not permitted by statutory regulation or exceeds the permitted use, you will need to obtain permission directly from the copyright holder. To view a copy of this licence, visit http://creativecommons.org/licenses/by/4.0/. The Creative Commons Public Domain Dedication waiver (http://creativeco mmons.org/publicdomain/zero/1.0/) applies to the data made available in this article, unless otherwise stated in a credit line to the data. 
to the behaviours detailed. This also has implications for the development and evaluation of interventions to change such behaviours and improve quality of care.

Keywords: Pharmacist, Professional behaviour, Practice standards, Behavioural specification

\section{Contributions to the literature}

- Behavioural specificity within pharmacy professional practice standards has not been previously explored.

- Behaviours in practice standards need to be specified appropriately to ensure that 1 ) the user can read, understand and action them and 2) it is possible to observe, measure and assess influences on, the said behaviours to improve quality of care.

- The researchers applied the Actor, Action, Context, Target, Time (AACTT) behavioural specification framework to review, for the first time, the specificity of behaviours in the Australian professional practice standards for pharmacists and found that the behaviours are poorly specified.

- Thus, these standards cannot be used in their current form to assess and review the behaviour of pharmacists for professional development or to support behaviour change intervention development.

\section{Background}

Practice standards are key to all aspects of healthcare [1]. Standards exist to promote delivery of consistent, high quality services and healthcare for patients, regardless of where or how they access the healthcare professional [2, $3]$. They are often written by governing bodies and professional organisations to dictate expected behaviours (or actions) of individuals acting in a particular context [1, 47]. Practice standards vary in terms of their specific purpose and form however they usually detail the minimum expected behaviours and conduct of the professional (e.g. how a health care professional responds to a request for medical information) $[6,8]$. Behaviours described in this context are perhaps better understood as actions, that is the things that the professional should do. For example, in the case of pharmacists, what they should do when dispensing a medication or providing medicines advice to a patient.

In Australia, the Professional Practice Standards for Pharmacists serve as a benchmark for pharmacists to ensure that they meet the expectations of the profession, society, other health professionals, funders and regulators [6]. To supply medicines subsidised by the government, Australian pharmacists must comply with these standards [6]. If pharmacists do not meet society's, other health professionals' or funding agencies' expectations of them, the consequences can be devastating, for the community, the pharmacist and the pharmacy profession. As inadequate professional behaviours may lead to detrimental health outcomes for individuals or limits on the individual pharmacists professional practice $[9,10]$. In such cases, practice standards can and have served as a framework to investigate alleged misconduct $[6,9]$. If practice standards are ambiguous, they may be interpreted differently by different professionals and patients may not receive the expected level of patient centred care. Practising according to the standards is intended to ensure that legal, ethical and effective healthcare services are consistently provided by pharmacists regardless of practice setting.

Despite the central role practice standards play in communicating professional behaviours, useability of these documents has not been previously investigated. Clinical Guidelines serve a similar purpose to practice standards and usually communicate behaviours in terms of the considerations and decisions a clinician should make when providing care to a patient $[2,3]$ (e.g. what blood pressure management medication they should prescribe someone diagnosed with moderate hypertension). Broader research on clinical guidelines frequently cites clarity of content and language as essential in producing actionable guidelines [11-18]. In this body of research it is commonly stated that behaviours in such guidelines should be specific and unambiguous [11-19]. Concrete language and minimal ambiguity are likely essential to any document that communicates behaviours to its reader, including professional practice standards. Understanding how behaviours are expressed in practice standards would contribute to understanding the extent to which these documents are fit for purpose in communicating professional behaviour.

Michie and Johnston [16] have suggested that specifying who, what, when, where and how often a behaviour should occur in clinical guidelines would ensure a clear understanding of the behaviour and increase the likelihood of it being enacted $[16,19]$. This level of specification also facilitates identification of barriers and enablers to the target population performing the behaviour [16, 19-21]. A rich understanding of the barriers and enablers to a target behaviour for a specific target population in a particular context can support the selection of theoretically congruent intervention components $[16,20$, 
21]. Such specification also supports the measurement of behaviours as part of intervention evaluation [18, 20-22]. Therefore, for the required behaviours to be measured, understood and improved, it is essential that practice standards are appropriately specified. This is vital for individuals to assess their own practice, and also for professional bodies or researchers to evaluate consistency and quality of practice within the profession.

Behaviour change science offers many theories, models and frameworks that support intervention development and evaluation. One such framework, The Behaviour Change Wheel $[20,21]$, outlines a variety of steps for intervention development starting with selection and specification of a target behaviour. The approach recommends that target behaviours are specified in terms of Who, What, When, Where, How Often and With Whom? [20, 21] Several other frameworks have been developed which are synonymous with and build on Michie's ideas. These frameworks also focus on specifying behaviours as part of a behavioural intervention design process [22-25]. The first of these frameworks was the Target, Action, Context, Time (TACT) framework [24]. Next came its extension the Target, Action, Context, Timing and Actor (TACT-A) framework. Here it was recognised that the original TACT framework was limited as it assumed that an individual was performing the behaviour for themselves and did not specify 'who' needed to complete the action. This limited the practical application of the framework to behaviours where another individual is responsible for completing the action (e.g. a nurse taking a blood pressure reading for a patient), thus this extension included the addition of the 'A: Actor - person who performs the action. [22, 25, 26] The most recent iteration of these frameworks is the Action, Actor, Context, Target, Time (AACTT) framework, that includes the Actor extension, additional detail added to the Target definition and a re-ordering of the components to improve its useability [23]. As well as being the most recent attempt to bring together the key criteria required for specifying behaviours, the AACTT framework is particularly useful when exploring complex behavioural problems that involve sequences of behaviours performed by different people [23]. For example, supplying a prescription medication to a patient would involve the prescriber, patient and a pharmacist, at a minimum. The authors wrote AACTT with the intention of specifying behaviour as a target for change, however they also suggested that 'AACTT is compatible with any theory, model or framework in which behaviour is the focus of inquiry. [23] Thus, it is not unreasonable to think that this framework and the theory it draws upon may be useful in other contexts, albeit some adaptation to domains may be needed.
Previous work has adapted and applied the TACT-A framework for other purposes including, to analyse the specificity of behaviours in various document types $[18,26]$. Gould et al. [26] utilised the TACT-A framework to review the content of feedback documents used to audit blood transfusion practice in healthcare settings in the United Kingdom. The results were intended to identify areas for improvement in these feedback processes and develop intervention guidance documents and training materials to improve these audit/feedback processes [26]. Similarly, in the United Kingdom, Smith and colleagues used the TACT-A framework to evaluate behaviours detailed in a policy documents from acute National Health Service trusts, to operationalise clinician responses to deteriorating patients in hospital wards [18]. They found a lack of specification of the Actor, Target, Time and Context that may be problematic in this setting and have since sought to further explore these actions and their influences, with the intention of designing a behavioural intervention to improve them $[18,27,28]$. These studies confirm that it is possible to adapt and use behavioural specification frameworks in more innovative ways to retrospectively assess specificity in different types of documents.

A literature review did not identify any previous research applying the AACTT framework to the review of behaviours in documents. Furthermore, no studies were found to review the useability of professional practice standards of any kind, let alone the specificity of the behaviours detailed in professional practice standards for pharmacists. As part of a broader project seeking to measure and influence the professional behaviour of pharmacists in Australia, the present study aimed to determine if behaviours described in the Professional Practice Standards for Australian Pharmacists specify Action, Actor, Context, Target and Time.

\section{Methods}

Professional practice standards for Australian pharmacists

This research reviewed the Professional Practice Standards for Australian Pharmacists, hereafter referred to as the practice standards [6]. This document applies to all practising pharmacists in Australia, regardless of role, scope, experience level or location of practice. Further, these practice standards have been reviewed and endorsed by all the relevant professional bodies, including the regulator, the Pharmacy Board of Australia. The practice standards contain 16 standards with independent statements entitled 'actions required' (referred to as action statements). For the 16 standards, each includes a preamble that consists of a standard statement along with the scope and background. Each standard lists 


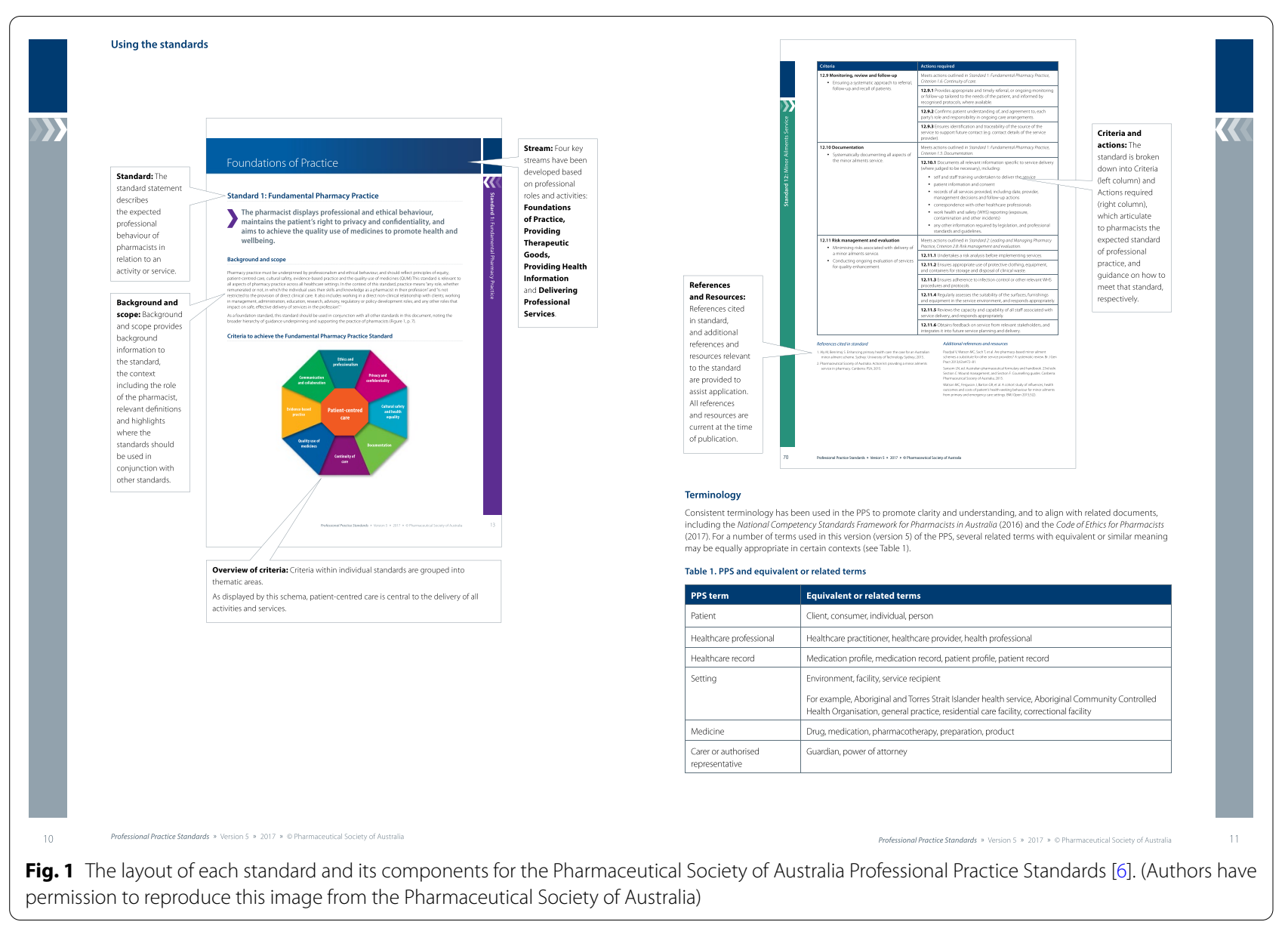

the specific criteria and related actions that a pharmacist is required to perform to meet the standard. The action statements are presented as tabulated information alongside the standard criteria [6]. The document is intended to be read and interpreted in its entirety to provide context to each individual criteria and action statement (Fig. 1).

Given the practice standards are a text rich document a directed content analysis approach was undertaken $[18,26,29,30]$. This type of analysis involves deductive coding of the text data where initial codes are derived from existing theory [29]. In this case, the theory that behavioural specification is important in documents that direct a professional's behaviour and the AACTT behavioural specification framework criterion [16, 23]. The initial codes derived from the AACTT framework (which represents the existing theory) were then adapted through the development of operational definitions, before being systematically applied to code the text data for analysis with the intention of identifying themes and patterns. No specific guidelines for reporting content analysis were identified by the researchers. Given content analysis is traditionally a qualitative method this study is reported according to the Consolidated criteria for reporting qualitative studies (COREQ): 32-item checklist [31] (Appendix 1).

\section{Familiarisation and identification of behaviours}

The practice standards were independently read and reviewed by two researchers (DM, DD). One researcher had a professional background as a pharmacist (DM) and the second as a behavioural scientist (DD), ensuring both relevant areas of expertise were represented in each stage of the study. The researchers focused attention on the structure and layout of the document with the aim to understand the location, sequence, presentation of information and the language use. During subsequent readings of the document, the researchers aimed to familiarise themselves with the presence of behaviours within the document. Behaviours were defined as actions that could or should be undertaken during the course of professional responsibilities, duties or employment as a pharmacist. Both reviewers 
independently determined that the action statement sections of each standard were the part of the document where behaviours were consistently described. Both researchers (DM, DD) agreed that the criteria, scope, background and standard statement sections did not contain specific actions but provided broad contextual information (e.g. Actor, Context, Target and Time) for the action statements.

\section{Data extraction}

The first 12 pages of the practice standards and appendices were excluded from the analysis as these sections were considered to introduce, orientate and supplement the practice standards rather than provide actionable content. Therefore, data (action statements and accompanying information) were extracted from within the main body of the practice standards document from page 13 to 95 .

One researcher (DM) extracted verbatim the action statements from the document and sought contextual information (Actor, Context, Target and Time) from preceding sections (criteria, scope, background and standard statement sections) if required. The actions were extracted as they contained the described behaviours. The extracted information included sufficient referencing to locate the information within the document (e.g. standard 2, criteria 3, action 5 was referred to as 2.3.5). Actions were excluded where they referred directly to other action statements (e.g. see "Meets actions outlined in Standard 1: Fundamental Pharmacy Practice, Criterion 1.1: Patient-centred care") [6].

Details on the authors, version number, year published, publisher, scope and purpose of the practice standards were extracted for referencing and context.

\section{Deductive codebook development}

The research team (DM, DD) used an iterative process to create a deductive code book that could be used to review the identified behaviours (action statements) against the Action, Actor, Context, Target, Time (AACTT) criteria (Table 1). To ensure consistent coding the researchers adapted the original AACTT criteria definitions for application in this context (reviewing practice standards), rather than its original purpose (specifying behaviours for behaviour change intervention design). Changes included revising the phrase 'behaviour that needs to change' to 'behaviour' for the definition of Action and clarifying that the definition of Time for this study included when a situation was dependent on a set of circumstances (Table 1). The action statements in the practice standards were also noted to refer to other documents (e.g. legislation, guidelines) essential to complete said actions. To account for these, additional criteria were added to the assessment of Action for the review, including assessment of whether the action referred to another document and if any other document referred to was adequately named and accessible (Table 1). A set of decision criteria was also developed (e.g. yes/no/more information needed/ not necessary). Their associated definitions and example applications can be viewed in the code book (Table 1).

The adapted AACTT criterion definitions were developed to assess the extracted data through the application of the associated decision criteria. Illustrative phrases were identified to support the decision-making. The application of the definition to the extracted action statements allowed the researchers (DM, DD) to assess if the statement met each AACTT criteria. If necessary, the researchers worked through the document in an iterative manner to identify if information pertaining to the four contextual criteria (Actor, Context, Target and Time) were available when the action statement was read in context (e.g. read with the previous sections of the standard, namely the criteria, scope, background and standard statement sections).

To ensure consistency, ambiguous verbs (used to describe the actions of a behaviour) identified in the practice standards were tabulated with their dictionary definition and whether their use indicated discrete and observable actions (Table 2). For example, the non-specific verb 'ensure' was identified in the document to describe behaviours (e.g. ensuring something is undertaken). Ensure was considered to be neither discrete nor observable so each time it occurred in the document it was coded as "No" (e.g. criteria not met). This table supported consistent analysis and application of the codebook during the coding process.

\section{Application of codebook}

Once both researchers (DM, DD) were satisfied with the definitions, the standardised deductive codebook was applied to the extracted action statements using a directed content approach. One pharmacist researcher (DM) initially applied the codebook to the action statements. A second researcher (DD) independently checked the coding for $20 \%$ of the data pertaining to the individual action statements. The data (action statements) for the final check were selected through use of a random number generator. The row of data (action statement) from the database that corresponded to the number generated was then checked by the second researcher (DD). These included a selection of 


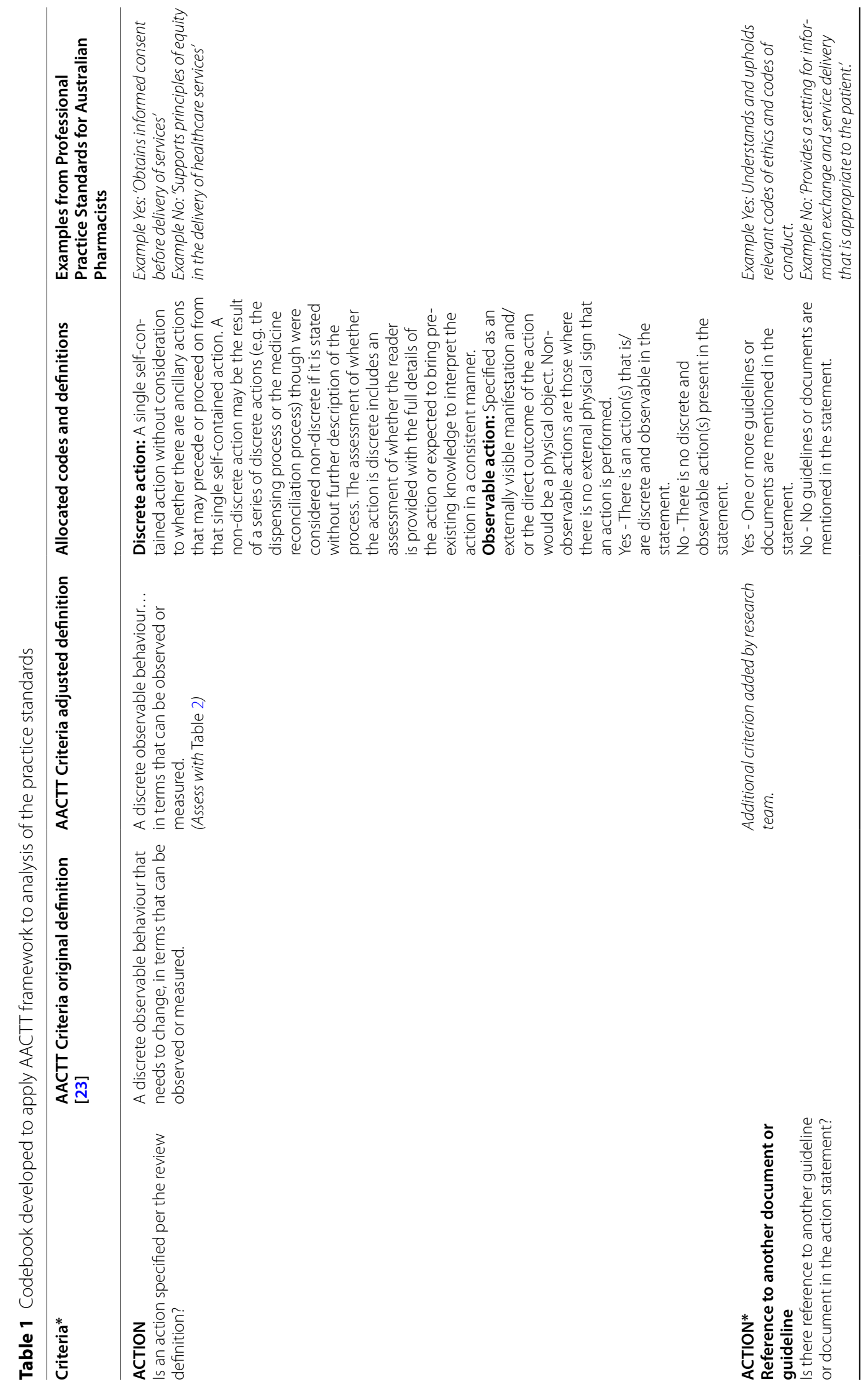




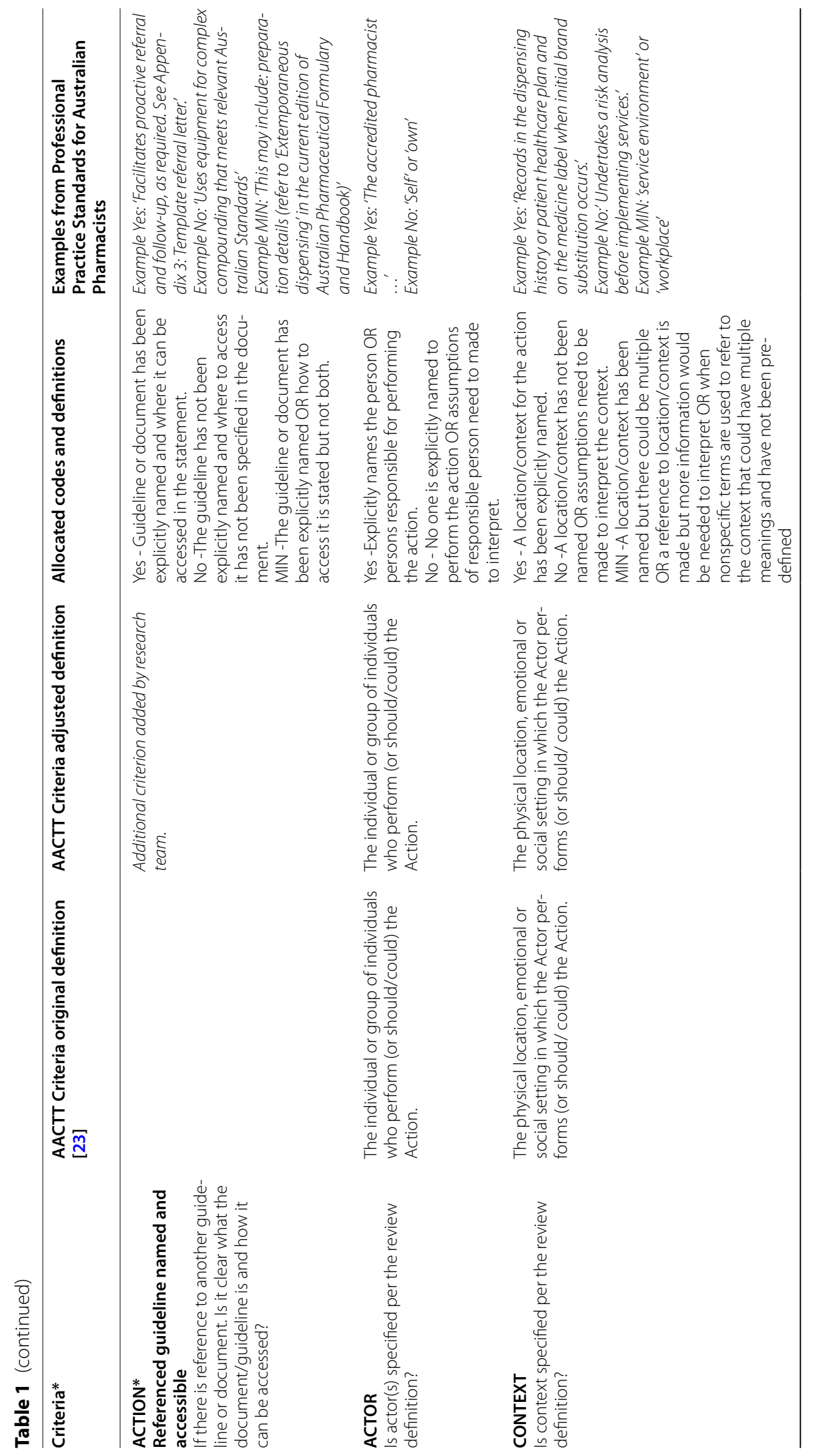




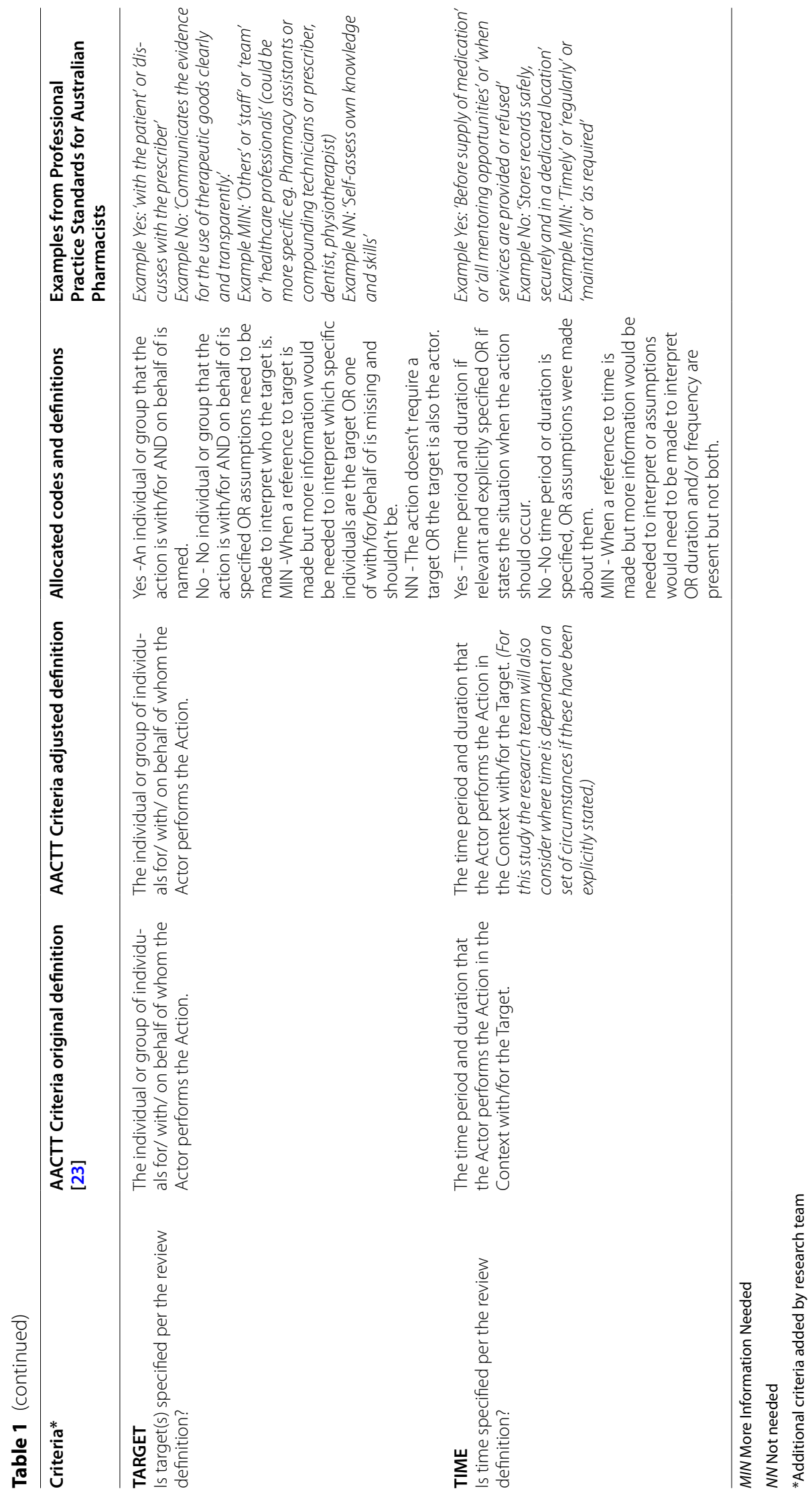




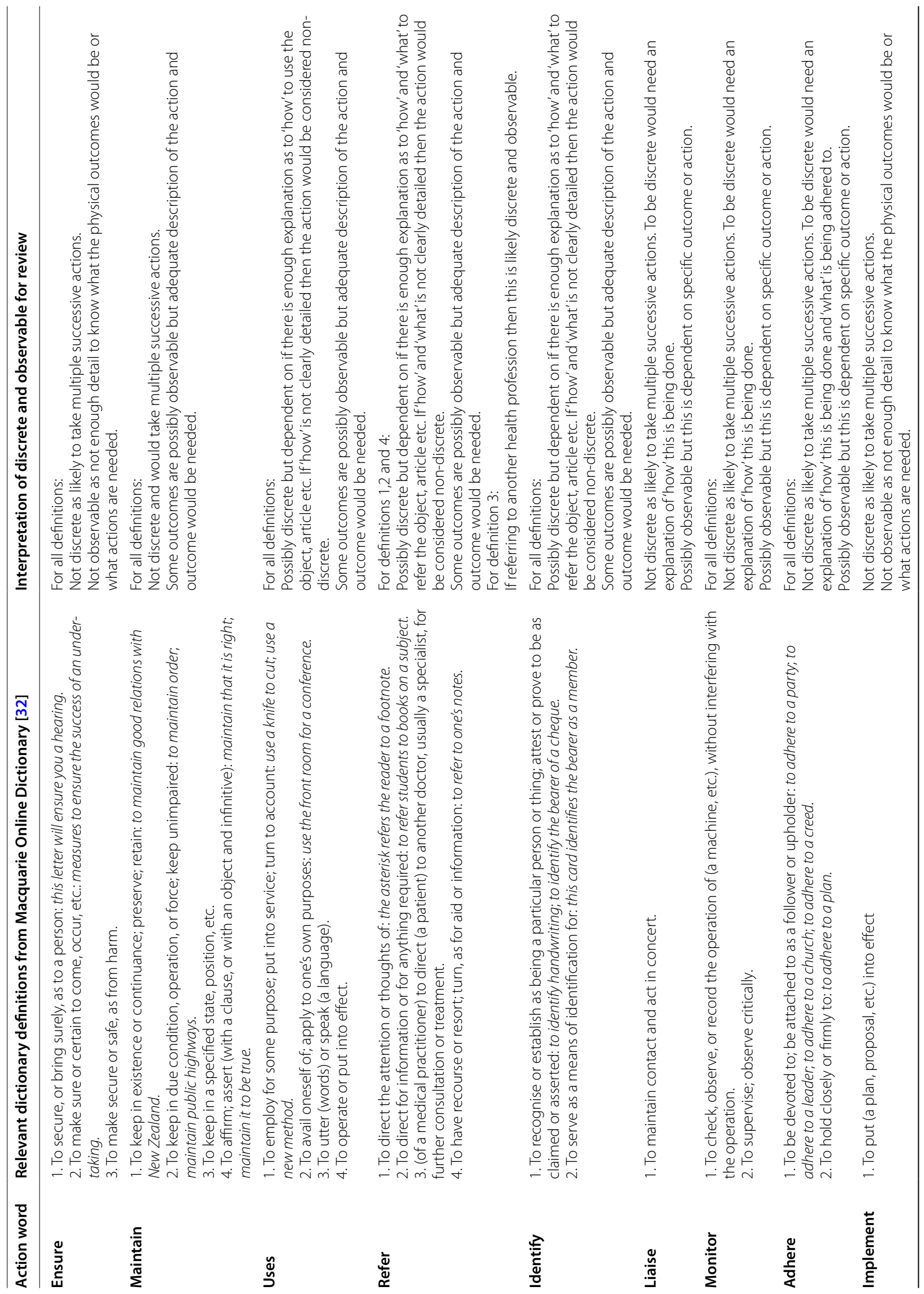




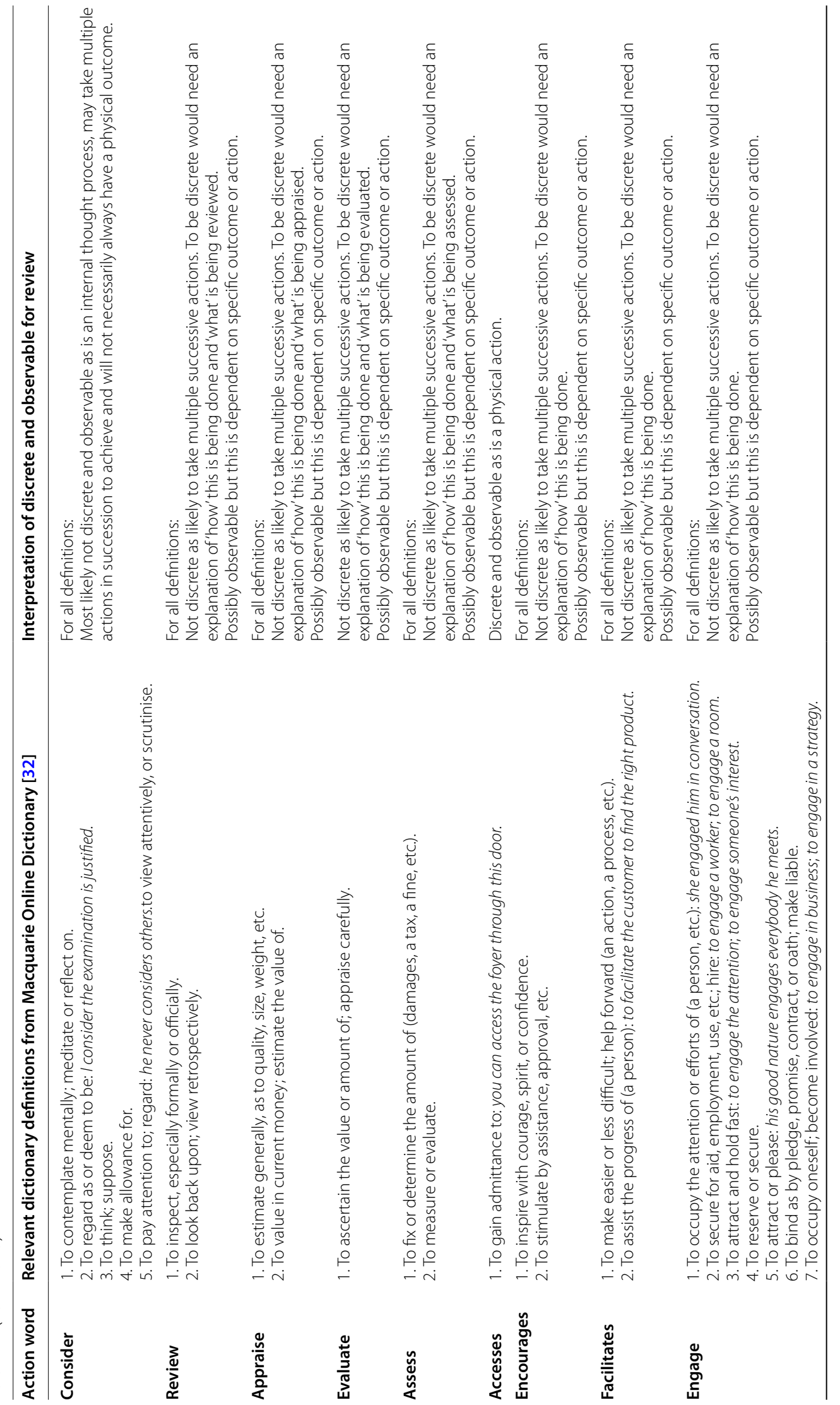




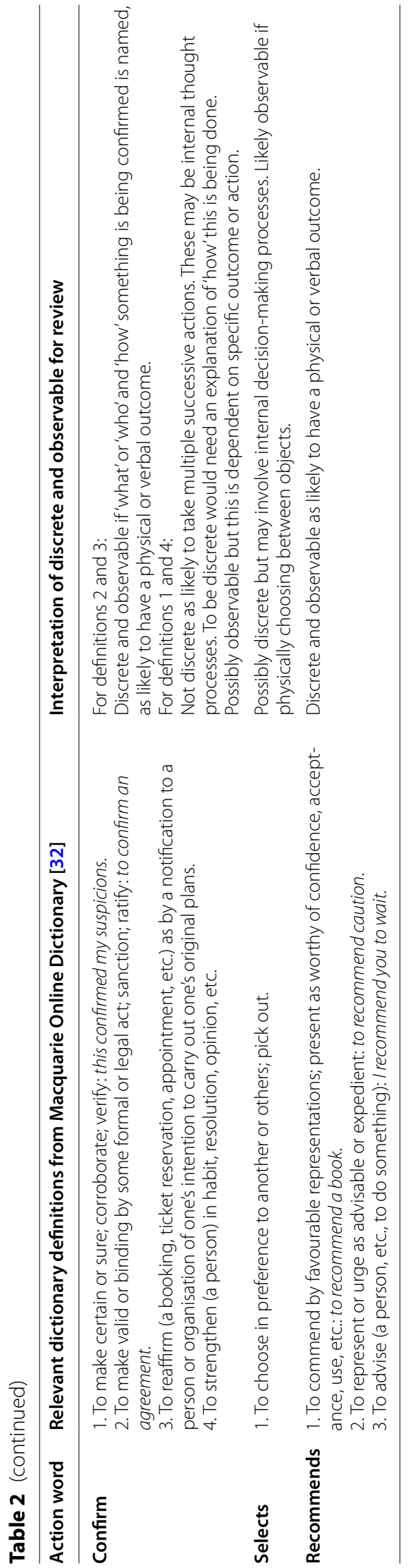


data ( $n=154,20 \%$ of action statements) from each of the 16 standards. Any differences identified during this check were resolved through discussion (DM, DD). The definitions were clarified again at this time to reduce ambiguity in interpretation by the researchers. One researcher (DM) then went through and reviewed all of the data to reflect the minor clarification changes that had been made to the codebook as a result of the $20 \%$ check.

\section{Data analysis}

Results were summarised for each criterion and code using frequencies and proportions calculated in the latest version of Microsoft Excel.

\section{Results}

The practice standards contain 768 independent action statements over the 16 different standards. The assessments for the Action, Actor, Context, Target and Time criteria of the action statements from 'Standard 1- Fundamental Pharmacy Practice' through to 'Standard 16- Harm Minimisation', are presented in Tables 3 and 4. The summary of the background, standard statements, and criteria assessments for Actor, Context, Target and Time can be viewed in Table 5. The application of the criteria and potential improvements have been presented using extracted action statements as illustrative examples in Table 6. Results for each component of the AACTT will be discussed separately below.

\section{Is ACTION specified in the action statements of the practice standards?}

At least one discrete and observable behaviour was described in over one-third of action statements $(n=300,39 \%)$ (Table 3). A further 26 (3\%) detailed more than one discrete and observable behaviour. Data for the assessments on actor, context, target and time criteria for each action statement is summarised in Table 4. Most times where the specificity criteria were not met, this was due to the verbs used to describe the action (Table 6, examples 1-4). One hundred and forty-eight (19\%) action statements referenced other documents, legislation or guidelines necessary to access or understand in order to complete the specified action. Details to facilitate access to these additional resources were present in a minority of statements $(n=20,14 \%)$. Partial resource details were missing for $25(17 \%)$ of these additional resources (Table 6 , example 5 ).

\section{Is ACTOR specified in the action statements of the practice} standards?

None of the action statements specified an actor (Table 4). It is likely assumed that the individual reading the document would be a pharmacist and that the pharmacist is the actor in each action statement. However, sometimes further clarity about which pharmacist should complete the action would assist with interpretation (e.g. pharmacist accredited to provide immunisations or pharmacy owner) (Table 6, examples 6 and 7). While 'pharmacist' was not specified as the actor in the criteria of each standard, it was specified in the standard statement and background and scope sections (Table 5).

\section{Is CONTEXT specified in the action statements} of the practice standards?

Twenty-five (3\%) action statements explicitly specified a context for the physical location. A further 35 (5\%) provided partial information regarding context (Table 4). Context was not specified in any standard statements. Context was specified once in the background and scope of one standard, and rarely in criteria of each standard (Table 5). There were several action statements that utilised the word 'service' with an inference to referencing a physical location. While a 'service' may have referred to a fixed physical location and therefore may have provided context, it could not be ascertained clearly that this was the case (Table 6, example 8). Some action statements had a broad reference to a physical location such as 'workplace,' however these could also be further specified or defined for each standard (Table 6, example 9).

The AACTT definition of context includes emotional context (e.g. stressful or calm) and social setting (e.g. one-on-one interaction or with both patient and carer present) in addition to the physical location. The researchers did not detect any action statements that provided either emotional context or social setting in the analysis.

\section{Is TARGET specified in the action statements of the practice standards?}

The target was specified in 131 (17\%) action statements and $36(5 \%)$ did not require a target (Table 4). A further 303 (39\%) provided partial information on the target. This information was specified or partially specified in the standard statement, background and scope and criteria of each standard (Table 5). Most times non-specific terms such as 'staff' or 'other healthcare workers' were used when further specification could have been made 
Table 3 Summary of all action statements ACTION criteria analysis by standard

\begin{tabular}{|c|c|c|c|c|c|c|}
\hline \multirow[b]{2}{*}{ Standard } & \multirow{2}{*}{$\begin{array}{l}\text { Number with } \\
\text { behaviourally } \\
\text { relevant content } \\
\text { No. }\end{array}$} & \multirow{2}{*}{$\begin{array}{l}\text { Action statements } \\
\text { with discrete } \\
\text { observable actions } \\
\text { Meets criteria } \\
\text { No. }(\%)\end{array}$} & \multirow{2}{*}{$\begin{array}{l}\text { Action statements } \\
\text { with more than one } \\
\text { discrete observable } \\
\text { actions } \\
\text { No. }(\%)\end{array}$} & \multirow{2}{*}{$\begin{array}{l}\text { Action statements } \\
\text { that's ACTION } \\
\text { referenced other } \\
\text { documents } \\
\text { No. }(\%)\end{array}$} & \multicolumn{2}{|c|}{$\begin{array}{l}\text { Action statements that's } \\
\text { reference to other documents } \\
\text { explicitly named and said } \\
\text { how to access the document }\end{array}$} \\
\hline & & & & & $\begin{array}{l}\text { Specified } \\
\text { No. }(\%)\end{array}$ & $\begin{array}{l}\text { Partially specified } \\
\text { No. (\%) }\end{array}$ \\
\hline $\begin{array}{l}\text { Standard 1: Funda- } \\
\text { mental Pharmacy } \\
\text { Practice }\end{array}$ & 48 & 22 (46\%) & $2(4 \%)$ & $8(17 \%)$ & $4(50 \%)$ & 0 \\
\hline $\begin{array}{l}\text { Standard 2: Leading } \\
\text { and Managing Phar- } \\
\text { macy Practice }\end{array}$ & 51 & 16 (31\%) & $1(2 \%)$ & $11(22 \%)$ & 0 & $1(9 \%)$ \\
\hline $\begin{array}{l}\text { Standard 3: Dispens- } \\
\text { ing and Other Supply } \\
\text { Arrangements }\end{array}$ & 70 & 36 (51\%) & $3(4 \%)$ & 14 (20\%) & $1(7 \%)$ & $4(29 \%)$ \\
\hline $\begin{array}{l}\text { Standard 4: Provision } \\
\text { of Non-prescription } \\
\text { Medicines and Thera- } \\
\text { peutic Devices }\end{array}$ & 30 & $16(53 \%)$ & $2(7 \%)$ & $7(23 \%)$ & 0 & $2(29 \%)$ \\
\hline $\begin{array}{l}\text { Standard 5: Com- } \\
\text { pounding }\end{array}$ & 75 & $36(48 \%)$ & 10 (13\%) & $22(29 \%)$ & $6(27 \%)$ & $5(23 \%)$ \\
\hline $\begin{array}{l}\text { Standard 6: Medicines } \\
\text { Information }\end{array}$ & 23 & $3(13 \%)$ & $1(33 \%)$ & 0 & 0 & 0 \\
\hline $\begin{array}{l}\text { Standard 7: Health } \\
\text { Promotion and } \\
\text { Education }\end{array}$ & 21 & $6(29 \%)$ & 0 & $1(5 \%)$ & 0 & 0 \\
\hline $\begin{array}{l}\text { Standard 8: Counsel- } \\
\text { ling }\end{array}$ & 36 & 14 (39\%) & $1(3 \%)$ & $4(11 \%)$ & 0 & 0 \\
\hline $\begin{array}{l}\text { Standard 9: Collabora- } \\
\text { tive Care }\end{array}$ & 52 & $12(23 \%)$ & $1(2 \%)$ & $7(13 \%)$ & 0 & 0 \\
\hline $\begin{array}{l}\text { Standard 10: Screen- } \\
\text { ing and Risk Assess- } \\
\text { ment }\end{array}$ & 36 & 10 (28\%) & 0 & $10(28 \%)$ & $2(20 \%)$ & $2(20 \%)$ \\
\hline $\begin{array}{l}\text { Standard 11: Vaccina- } \\
\text { tion Service }\end{array}$ & 65 & $26(40 \%)$ & $1(2 \%)$ & $14(22 \%)$ & 0 & $4(29 \%)$ \\
\hline $\begin{array}{l}\text { Standard 12: Minor } \\
\text { Ailments Service }\end{array}$ & 39 & 13 (33\%) & 0 & $9(23 \%)$ & $1(11 \%)$ & $1(11 \%)$ \\
\hline $\begin{array}{l}\text { Standard 13: Disease } \\
\text { State Management }\end{array}$ & 47 & 16 (34\%) & $1(2 \%)$ & 10 (21\%) & $2(20 \%)$ & $3(30 \%)$ \\
\hline $\begin{array}{l}\text { Standard 14: Medica- } \\
\text { tion Review }\end{array}$ & 52 & 31 (60\%) & $3(6 \%)$ & 10 (19\%) & $1(10 \%)$ & 0 \\
\hline $\begin{array}{l}\text { Standard 15: Dose } \\
\text { Administration Aid } \\
\text { Service }\end{array}$ & 73 & 21 (29\%) & 0 & 10 (14\%) & $2(20 \%$ & $1(10 \%)$ \\
\hline $\begin{array}{l}\text { Standard 16: Harm } \\
\text { Minimisation }\end{array}$ & 50 & $22(44 \%)$ & 0 & $11(22 \%)$ & $1(9 \%)$ & $2(18 \%)$ \\
\hline Total & 768 & 300 (39\%) & $26(3 \%)$ & 148 (19\%) & $20(14 \%)^{a}$ & $25(17 \%)^{\mathrm{a}}$ \\
\hline
\end{tabular}

$\%$ calculated per total no. of behaviourally relevant actions in each standard unless otherwise specified

a \% calculated per total action statements that referenced other documents

(Table 4, example 10). In other cases, the 'on behalf of' was specified, but the 'who with' required further clarification (Table 6, example 11).
Is TIME specified in the action statements of the practice standards?

Time was specified within $88(11 \%)$ action statements with partial information provided by a further 120 (16\%) action statements (see Table 4). Time was at least partially specified in most standard statements, 
Table 4 Summary of action statements ACTOR, CONTEXT, TARGET and TIME criteria analysis by standard

\begin{tabular}{|c|c|c|c|c|c|c|c|c|c|}
\hline \multirow[b]{2}{*}{ Standard } & \multirow{2}{*}{$\begin{array}{l}\text { Actions with } \\
\text { behaviourally } \\
\text { relevant } \\
\text { content } \\
\text { No. }\end{array}$} & \multirow{2}{*}{$\begin{array}{l}\text { ACTOR(s) } \\
\text { was } \\
\text { specified }\end{array}$} & \multicolumn{2}{|c|}{ CONTEXT was specified } & \multicolumn{3}{|c|}{ TARGET(s) was specified } & \multicolumn{2}{|c|}{ TIME was specified } \\
\hline & & & $\begin{array}{l}\text { Meets } \\
\text { criteria } \\
\text { No. (\%) }\end{array}$ & $\begin{array}{l}\text { Partially } \\
\text { meets } \\
\text { criteria } \\
\text { No. (\%) }\end{array}$ & $\begin{array}{l}\text { Meets } \\
\text { criteria } \\
\text { No. (\%) }\end{array}$ & $\begin{array}{l}\text { Partially } \\
\text { meets } \\
\text { criteria } \\
\text { No. (\%) }\end{array}$ & $\begin{array}{l}\text { Not } \\
\text { necessary } \\
\text { No. (\%) }\end{array}$ & $\begin{array}{l}\text { Meets } \\
\text { criteria } \\
\text { No. (\%) }\end{array}$ & $\begin{array}{l}\text { Partially } \\
\text { meets } \\
\text { criteria } \\
\text { No. (\%) }\end{array}$ \\
\hline $\begin{array}{l}\text { Standard 1: } \\
\text { Fundamental } \\
\text { Pharmacy } \\
\text { Practice }\end{array}$ & 48 & 0 & 0 & $5(10 \%)$ & $14(29 \%)$ & $23(48 \%)$ & $1(2 \%)$ & $8(17 \%)$ & $6(13 \%)$ \\
\hline $\begin{array}{l}\text { Standard 2: } \\
\text { Leading and } \\
\text { Managing } \\
\text { Pharmacy } \\
\text { Practice }\end{array}$ & 51 & 0 & 0 & $6(12 \%)$ & $2(4 \%)$ & $28(55 \%)$ & $7(14 \%)$ & $2(4 \%)$ & $7(14 \%)$ \\
\hline $\begin{array}{l}\text { Standard 3: } \\
\text { Dispensing } \\
\text { and Other } \\
\text { Supply } \\
\text { Arrange- } \\
\text { ments }\end{array}$ & 70 & 0 & $5(7 \%)$ & $2(3 \%)$ & 17 (24\%) & $28(40 \%)$ & $2(3 \%)$ & $12(17 \%)$ & $9(13 \%)$ \\
\hline $\begin{array}{l}\text { Standard 4: } \\
\text { Provision of } \\
\text { Non-prescrip- } \\
\text { tion Medi- } \\
\text { cines and } \\
\text { Therapeutic } \\
\text { Devices }\end{array}$ & 30 & 0 & $1(3 \%)$ & 0 & $8(27 \%)$ & $11(37 \%)$ & $2(7 \%)$ & $7(23 \%)$ & $4(13 \%)$ \\
\hline $\begin{array}{l}\text { Standard 5: } \\
\text { Compound- } \\
\text { ing }\end{array}$ & 75 & 0 & $3(4 \%)$ & $8(11 \%)$ & $4(5 \%)$ & $14(19 \%)$ & $5(7 \%)$ & $14(19 \%)$ & $20(27 \%)$ \\
\hline $\begin{array}{l}\text { Standard 6: } \\
\text { Medicines } \\
\text { Information }\end{array}$ & 23 & 0 & 0 & $1(4 \%)$ & $6(26 \%)$ & $13(57 \%)$ & $1(4 \%)$ & $2(9 \%)$ & $3(13 \%)$ \\
\hline $\begin{array}{l}\text { Standard 7: } \\
\text { Health Pro- } \\
\text { motion and } \\
\text { Education }\end{array}$ & 21 & 0 & $1(5 \%)$ & 0 & $1(5 \%)$ & $14(67 \%)$ & $1(5 \%)$ & $2(10 \%)$ & $1(5 \%)$ \\
\hline $\begin{array}{l}\text { Standard 8: } \\
\text { Counselling }\end{array}$ & 36 & 0 & $2(6 \%)$ & 0 & $11(31 \%)$ & $10(28 \%)$ & 0 & $3(8 \%)$ & $3(8 \%)$ \\
\hline $\begin{array}{l}\text { Standard 9: } \\
\text { Collaborative } \\
\text { Care }\end{array}$ & 52 & 0 & 0 & $2(4 \%)$ & $2(4 \%)$ & $31(60 \%)$ & $2(4 \%)$ & $1(2 \%)$ & $4(8 \%)$ \\
\hline $\begin{array}{l}\text { Standard 10: } \\
\text { Screening } \\
\text { and Risk } \\
\text { Assessment }\end{array}$ & 36 & 0 & $1(3 \%)$ & 0 & $7(19 \%)$ & $8(22 \%)$ & $4(11 \%)$ & $3(8 \%)$ & 7 (19\%) \\
\hline $\begin{array}{l}\text { Standard 11: } \\
\text { Vaccination } \\
\text { Service }\end{array}$ & 65 & 0 & 0 & $4(6 \%)$ & 12 (18\%) & 29 (45\%) & $2(3 \%)$ & $8(12 \%)$ & $12(18 \%)$ \\
\hline $\begin{array}{l}\text { Standard 12: } \\
\text { Minor Ail- } \\
\text { ments Service }\end{array}$ & 39 & 0 & 0 & $2(5 \%)$ & $6(15 \%)$ & 13 (33\%) & 0 & $3(8 \%)$ & $6(15 \%)$ \\
\hline $\begin{array}{l}\text { Standard 13: } \\
\text { Disease State } \\
\text { Management }\end{array}$ & 47 & 0 & 0 & $1(2 \%)$ & $10(21 \%)$ & $19(40 \%)$ & $4(9 \%)$ & $2(4 \%)$ & $5(11 \%)$ \\
\hline $\begin{array}{l}\text { Standard 14: } \\
\text { Medication } \\
\text { Review }\end{array}$ & 52 & 0 & $1(2 \%)$ & $3(6 \%)$ & 11 (21\%) & 25 (48\%) & 0 & $4(8 \%)$ & $7(13 \%)$ \\
\hline
\end{tabular}


Table 4 (continued)

\begin{tabular}{|c|c|c|c|c|c|c|c|c|c|}
\hline \multirow[b]{2}{*}{ Standard } & \multirow{2}{*}{$\begin{array}{l}\text { Actions with } \\
\text { behaviourally } \\
\text { relevant } \\
\text { content } \\
\text { No. }\end{array}$} & \multirow{2}{*}{$\begin{array}{l}\text { ACTOR(s) } \\
\text { was } \\
\text { specified }\end{array}$} & \multicolumn{2}{|c|}{ CONTEXT was specified } & \multicolumn{3}{|c|}{ TARGET(s) was specified } & \multicolumn{2}{|c|}{ TIME was specified } \\
\hline & & & $\begin{array}{l}\text { Meets } \\
\text { criteria } \\
\text { No. (\%) }\end{array}$ & $\begin{array}{l}\text { Partially } \\
\text { meets } \\
\text { criteria } \\
\text { No. (\%) }\end{array}$ & $\begin{array}{l}\text { Meets } \\
\text { criteria } \\
\text { No. }(\%)\end{array}$ & $\begin{array}{l}\text { Partially } \\
\text { meets } \\
\text { criteria } \\
\text { No. (\%) }\end{array}$ & $\begin{array}{l}\text { Not } \\
\text { necessary } \\
\text { No. (\%) }\end{array}$ & $\begin{array}{l}\text { Meets } \\
\text { criteria } \\
\text { No. (\%) }\end{array}$ & $\begin{array}{l}\text { Partially } \\
\text { meets } \\
\text { criteria } \\
\text { No. (\%) }\end{array}$ \\
\hline $\begin{array}{l}\text { Standard 15: } \\
\text { Dose Admin- } \\
\text { istration Aid } \\
\text { Service }\end{array}$ & 73 & 0 & $8(11 \%)$ & 0 & $10(14 \%)$ & $22(30 \%)$ & $3(4 \%)$ & $12(16 \%)$ & $16(22 \%)$ \\
\hline $\begin{array}{l}\text { Standard 16: } \\
\text { Harm Minimi- } \\
\text { sation }\end{array}$ & 50 & 0 & $3(6 \%)$ & $1(2 \%)$ & $10(20 \%)$ & $15(30 \%)$ & $2(4 \%)$ & $6(12 \%)$ & $9(18 \%)$ \\
\hline Total & 768 & 0 & $25(3 \%)$ & $35(5 \%)$ & $131(17 \%)$ & $303(39 \%)$ & $36(5 \%)$ & $88(11 \%)$ & $120(16 \%)$ \\
\hline
\end{tabular}

$\%$ calculated per total no. of behaviourally relevant actions in each standard

Table 5 Summary of Standard statement, Background and scope, and Criteria ACTOR, CONTEXT, TARGET and TIME criteria analysis by standard

\begin{tabular}{|c|c|c|c|c|c|c|c|c|c|c|c|c|}
\hline \multirow[b]{2}{*}{ Standard } & \multicolumn{3}{|c|}{$\begin{array}{l}\text { ACTOR(s) } \\
\text { was specified }\end{array}$} & \multicolumn{3}{|c|}{ CONTEXT was specified } & \multicolumn{3}{|c|}{ TARGET(s) was specified } & \multicolumn{3}{|c|}{ TIME was specified } \\
\hline & $\begin{array}{l}\text { Standard } \\
\text { statement }\end{array}$ & 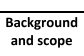 & Criteria & $\begin{array}{c}\text { Standard } \\
\text { statement }\end{array}$ & $\begin{array}{l}\substack{\text { Background } \\
\text { and scope }} \\
\end{array}$ & Criteria & $\begin{array}{c}\text { Standard } \\
\text { statement }\end{array}$ & $\begin{array}{l}\text { Background } \\
\text { and scope } \\
\end{array}$ & Criteria & $\begin{array}{c}\text { Standard } \\
\text { statement }\end{array}$ & $\begin{array}{l}\text { Background } \\
\text { and scope }\end{array}$ & Criteria \\
\hline Standard 1: Fundamental Pharmacy Practice & $\checkmark$ & $\checkmark$ & $\mathrm{X}$ & $\mathrm{X}$ & $\mathrm{X}$ & + & $\checkmark$ & $\mathrm{X}$ & + & $\mathrm{X}$ & $\checkmark$ & + \\
\hline $\begin{array}{l}\text { Standard 2: Leading and Managing Pharmacy } \\
\text { Practice }\end{array}$ & $\checkmark$ & $\checkmark$ & $\mathrm{X}$ & $\mathbf{x}$ & $\mathrm{X}$ & + & $\checkmark$ & + & + & $\mathrm{X}$ & + & $\mathrm{X}$ \\
\hline $\begin{array}{l}\text { Standard 3: Dispensing and Other Supply } \\
\text { Arrangements }\end{array}$ & $\checkmark$ & $\checkmark$ & $\mathrm{x}$ & $\mathrm{x}$ & $\mathrm{X}$ & $x$ & $\checkmark$ & + & + & $\mathrm{X}$ & $\checkmark$ & + \\
\hline $\begin{array}{l}\text { Standard 4: Provision of Non-prescription } \\
\text { Medicines and Therapeutic Devices }\end{array}$ & $\checkmark$ & $\checkmark$ & $\mathrm{X}$ & $\mathbf{x}$ & $\mathrm{X}$ & $\mathrm{x}$ & $\checkmark$ & $\checkmark$ & + & + & + & + \\
\hline Standard 5: Compounding & $\checkmark$ & $\checkmark$ & $\mathrm{x}$ & $\mathbf{x}$ & $\mathrm{X}$ & $\mathrm{x}$ & $\mathrm{X}$ & $\checkmark$ & + & $\checkmark$ & $\checkmark$ & + \\
\hline Standard 6: Medicines Information & $\checkmark$ & $\checkmark$ & $\mathrm{x}$ & $\mathrm{x}$ & $\mathrm{x}$ & $\mathrm{x}$ & + & + & + & $\mathrm{X}$ & $x$ & + \\
\hline Standard 7: Health Promotion and Education & $\checkmark$ & $\checkmark$ & $x$ & $x$ & $x$ & $x$ & $\checkmark$ & $\checkmark$ & + & $\mathrm{X}$ & $\checkmark$ & + \\
\hline Standard 8: Counselling & $\checkmark$ & $\checkmark$ & + & $\mathrm{x}$ & $\mathrm{X}$ & $x$ & $\checkmark$ & $\checkmark$ & + & $\checkmark$ & $\checkmark$ & + \\
\hline Standard 9: Collaborative Care & $\checkmark$ & $\checkmark$ & $x$ & $x$ & $\checkmark$ & + & + & + & + & $\mathrm{x}$ & $x$ & + \\
\hline Standard 10: Screening and Risk Assessment & $\checkmark$ & $\checkmark$ & $x$ & $\mathrm{x}$ & $x$ & $x$ & $\mathrm{X}$ & + & + & + & + & + \\
\hline Standard 11: Vaccination Service & $\checkmark$ & $\checkmark$ & $x$ & $x$ & $x$ & $x$ & $\checkmark$ & + & + & $\checkmark$ & $\checkmark$ & + \\
\hline Standard 12: Minor Ailments Service & $\checkmark$ & $\checkmark$ & $\mathrm{x}$ & $x$ & $x$ & $x$ & $\checkmark$ & $\checkmark$ & + & $\checkmark$ & $\checkmark$ & + \\
\hline Standard 13: Disease State Management & $\checkmark$ & $\checkmark$ & $\mathrm{X}$ & $\mathrm{x}$ & $\mathrm{x}$ & $x$ & + & + & + & $\checkmark$ & $\checkmark$ & + \\
\hline Standard 14: Medication Review & $\checkmark$ & $\checkmark$ & $\mathrm{X}$ & $\mathrm{x}$ & $\mathrm{x}$ & $x$ & + & $\checkmark$ & + & $\mathrm{X}$ & $\checkmark$ & + \\
\hline Standard 15: Dose Administration Aid Service & $\checkmark$ & $\checkmark$ & $x$ & $\mathrm{x}$ & $\mathrm{X}$ & $x$ & $\checkmark$ & $\checkmark$ & + & $\checkmark$ & $\checkmark$ & + \\
\hline Standard 16: Harm Minimisation & $\checkmark$ & $\checkmark$ & $\mathrm{x}$ & $x$ & $\mathrm{x}$ & $x$ & $\checkmark$ & + & + & $\checkmark$ & $\checkmark$ & + \\
\hline
\end{tabular}

background and scope and criteria for each standard (Table 5). Action statements sometimes stated that an action should be completed 'in a timely manner' which refers to how it should be completed rather than when. In other action statements, it was stated that the action should be undertaken 'as required,' which requires the reader to interpret the information (Table 6, example 12). It was rarely specified how often the action should occur. While it may be intended that the reader should assume the actions are ongoing when providing a service, this inference is not explicitly stated (Table 6 , example 13). 


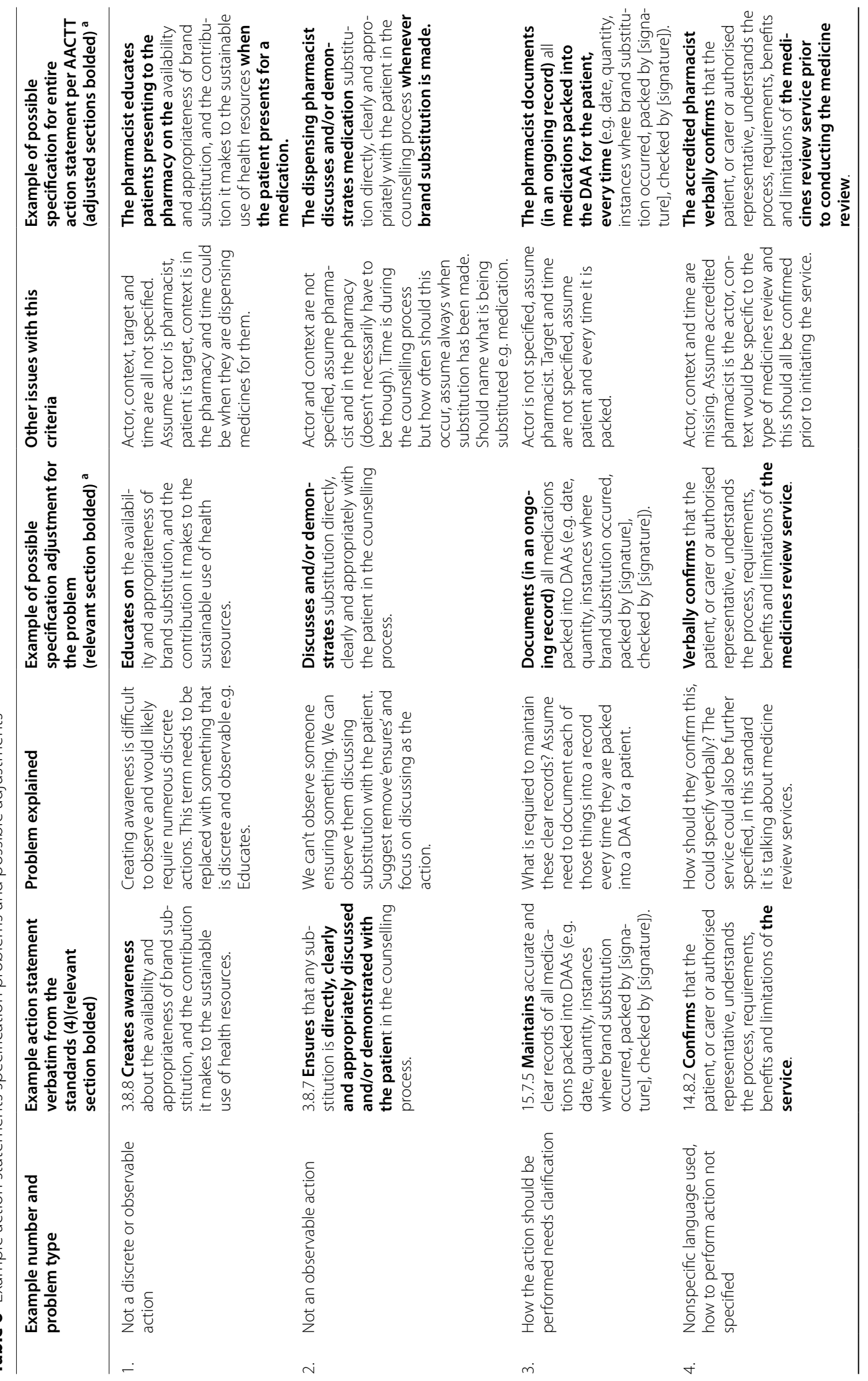




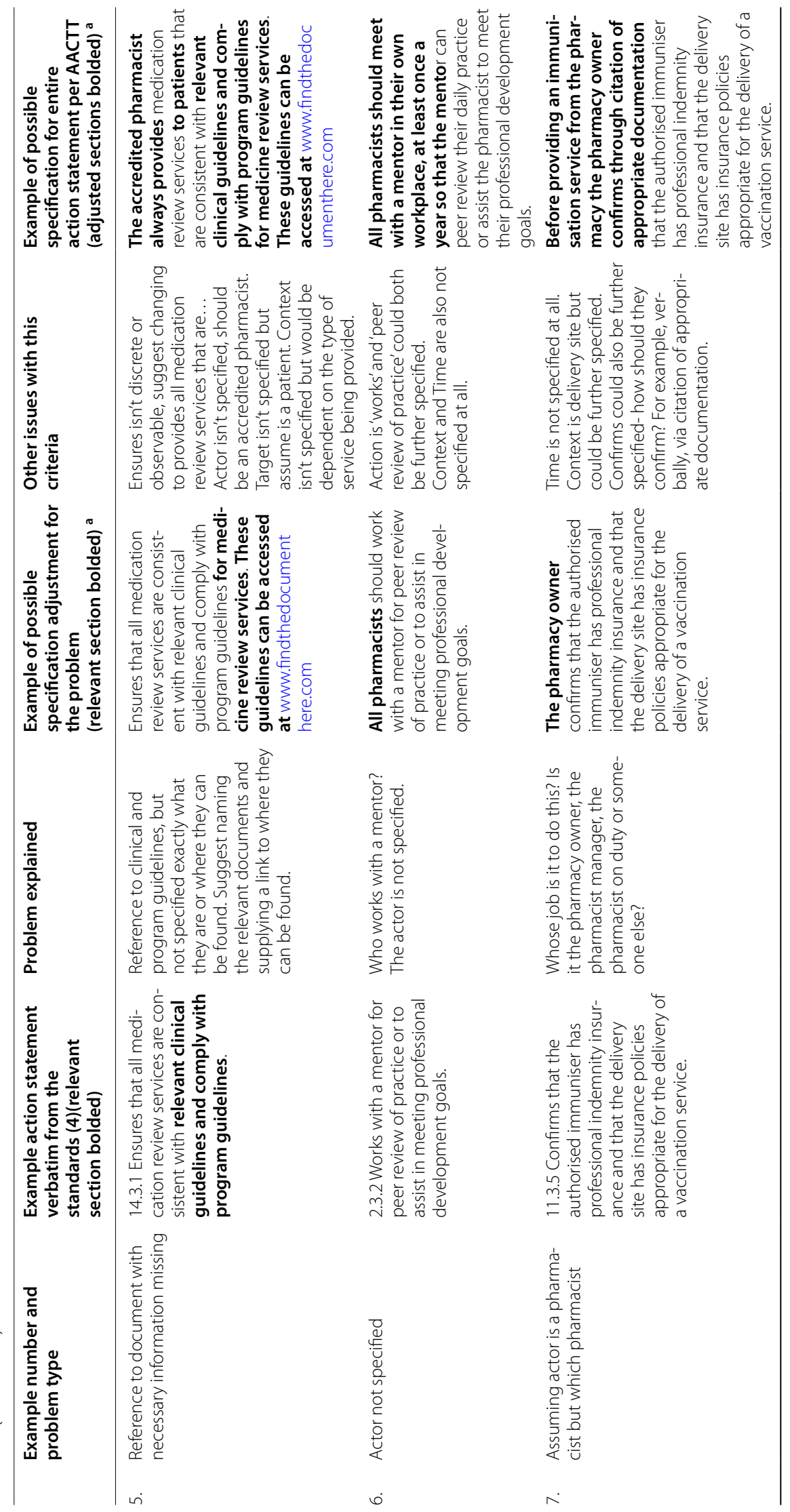




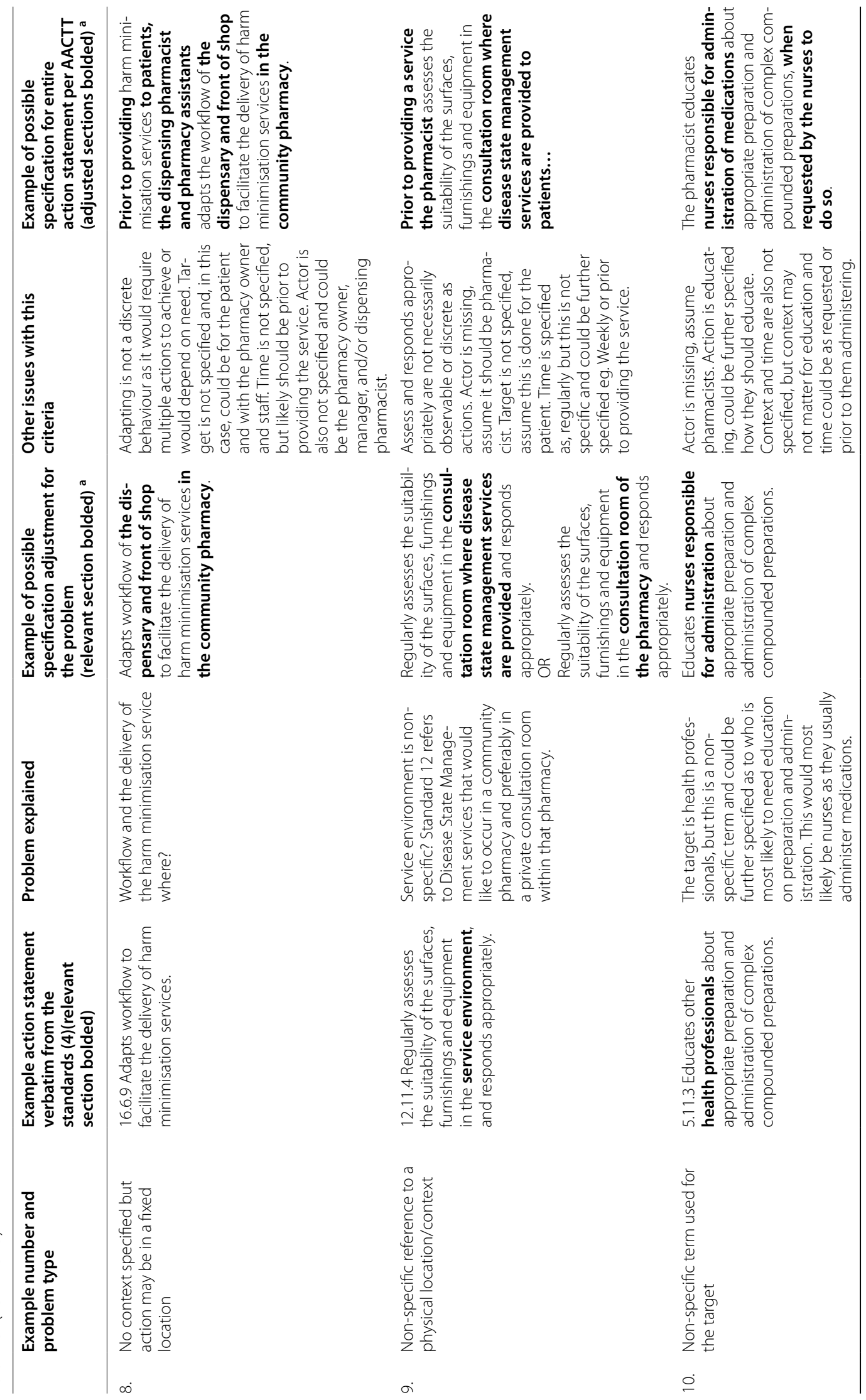




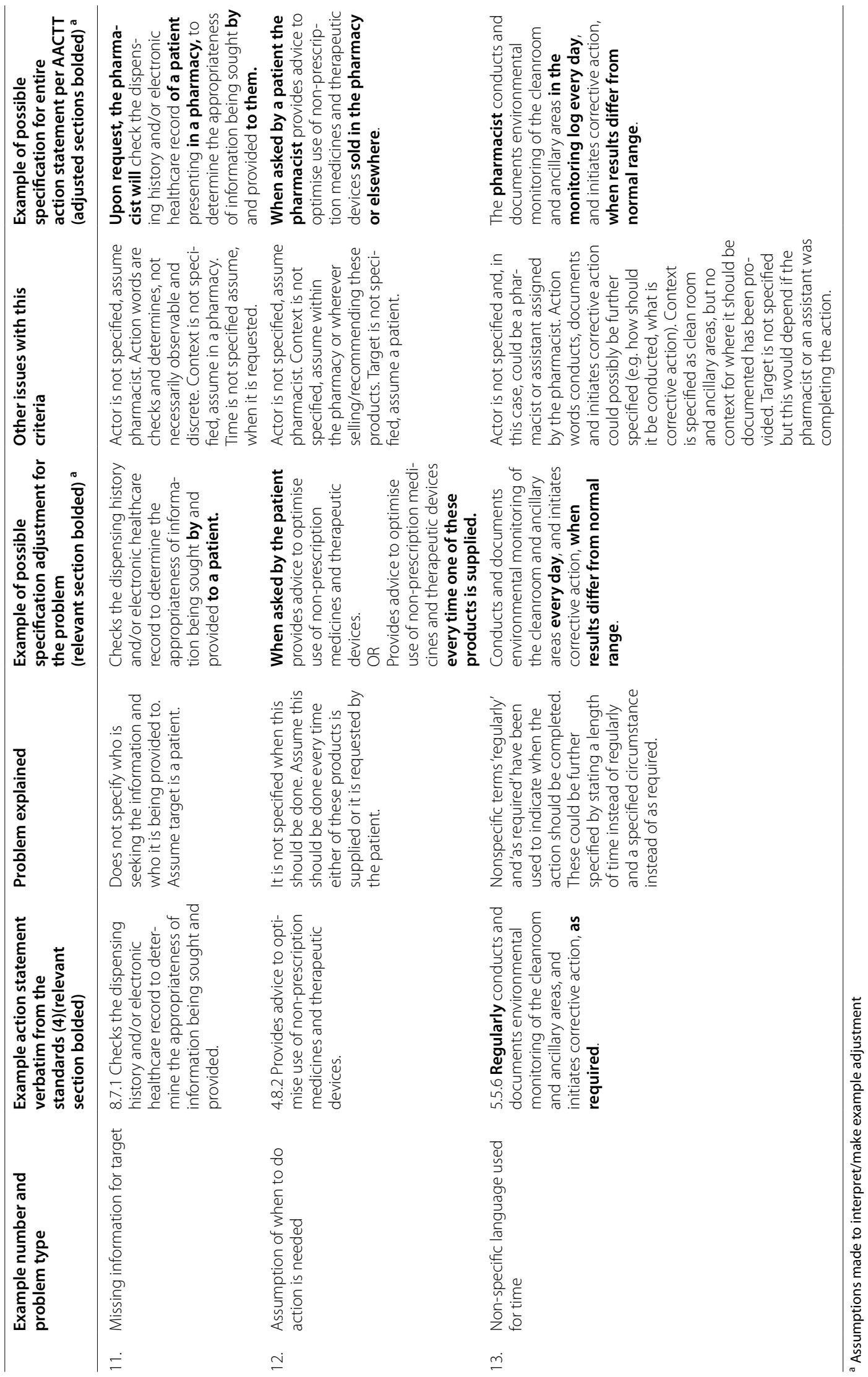




\section{Discussion}

This study sought to determine if behaviours described in the Professional Practice Standards for Australian Pharmacists specify Action, Actor, Context, Target and Time. Results demonstrated that these behaviours are not consistently specified in this way. The practice standards poorly specified action, most commonly due to the verbs used in the action statements being non-discrete and/or non-observable. Actor, Context, Target and Time, or a combination of these, were frequently missing or described ambiguously in the standards. The standards do not provide descriptive behaviours and instead detail broad behaviours in a non-specific manner. In their current form the standards require significant interpretation by the reader and would not be useful as a tool to measure, observe or design interventions to influence the professions' behaviour.

Smith et al. [18] found that the 'action statements' in policy documents intended to operationalise clinician responses to deteriorating patients in acute National Health Service hospital wards, more frequently specified all elements of the TACT-A criteria than the present study. 'Action' was the most frequently specified element in their analysis and in most cases they graded this as being reported specifically. Despite Smith et al. [18] more frequently identifying each criteria, similar issues were noted in this study for those criteria that were not specified adequately including: 'Time' was poorly specified owing to the use of terms that referenced a time but that still may be interpreted differently between individuals (e.g. urgently or timely) and 'Actor' was the least frequently specified element likely due to the documents assuming that the actor (or reader) should know who they are. Differences in results are likely due to the nature of the documents reviewed and the context in which they are used. The deteriorating patient documents reviewed by Smith et al. [18] likely provided more prescriptive actions given that they were policy documents and the behaviours detailed may be the difference between life and death for a hospitalised patient [18]. In comparison, the practice standards seem to be broad behavioural statements as they apply to an entire profession of individuals in all practice settings and roles.

Gupta et al. [13] explored sample recommendations from several Canadian clinical treatment guidelines (e.g. diabetes, asthma and ischaemic heart disease management) and discussed how they could be improved in terms of further specifying ambiguous terms. As in our study, the authors recognised that by not specifying exactly who (Actor) should do what, 'task ambiguity' is introduced [13]. Similarly, this study found that a lack of context introduces 'semantic ambiguity', where when taken out of context, the word or phrase (in our case behaviour) could have more than one interpretation [13]. While our work focussed on practice standards, that may serve a different purpose to clinical guidelines, considerations for specifying behaviours and recommendations are indeed similar.

\section{Implications}

The findings of this study demonstrate that, despite practice standards outlining the behaviours expected of the pharmacy profession, specificity has not been appropriately considered. While a high level of generalisability in these statements may be considered necessary when they are intended to apply to many different individuals in many different practice settings, the more generalisable they are the more difficult they are to use (i.e. for individuals to understand the minimum expected professional behaviours of pharmacists) $[13,19,20,25]$. This also limits their applicability to measure and evaluate the practice of pharmacists, explore influences on the desired behaviours and develop interventions to increase their likelihood of occurrence.

The lack of specificity identified may lead to inconsistent interpretation of the behaviours contained and as a result inconsistent practice by Australian pharmacists. This may be particularly problematic for pharmacist-patient relationships that are built on trust, where inconsistency in interactions for medicines and medicines information between pharmacist may confuse or undermine this relationship, preventing provision of care [33, 34]. Where a pharmacist's practice is under review by the Pharmacy Board of Australia or other regulator there may be a disconnect between the expectation and interpretation of the standards by the regulator versus the pharmacist, resulting in confusion and at worst, reprimand. Similar issues may arise where practising to the standards is required for renumeration, where the viability of the service may be put at risk due to unclear expectations. Further, if behaviours in the standards are not clearly specified then individuals may struggle to use them to review their own practice and identify continuing professional development opportunities to address their deficits. Given these standards were modelled on documents from other countries it is possible that they may have the same issue. As this was the first study of its kind to evaluate practice standards and more specifically pharmacist professional practice standards, we do not know to what extent this may be an issue outside the Australian context. 
Behavioural specificity should be considered when writing practice standards for any profession, not just pharmacists. The researchers suggest that standard developers apply behavioural specification at the smallest possible unit or wherever an action is described. Specifying Actor, Context, Target and Time in other sections, such as the background or scope sections, may dilute important information and make it less accessible. Where behavioural information is separated out to background sections for formatting it should be sign posted as to which actions the information applies, for example 'this standard applies to all community pharmacists regardless of current practice.' The researchers acknowledge that the level of detail provided and length of the document would need to be balanced with practical useability for its intended audience. However, digital formats could serve to improve and tailor the user experience in this case (e.g. broad statements that when clicked on offered specified examples of the behaviour).

This study builds upon previous work to demonstrate that researchers can adapt behavioural specification frameworks to evaluate behavioural descriptions in guidelines, protocols and now for the first-time, professional practice standards $[16,18]$. It confirms that this type of review can highlight areas of ambiguity that may prevent ease of interpretation and therefore implementation and evaluation of behaviours in these documents. Thus, with some adaptation these findings have highlighted the AACTT framework's useability, applicability and acceptability in a setting where behaviour change and intervention design are not necessarily the immediate focus. The changes made to the framework in this study may serve as a consideration for future iterations of the framework to improve its applicability and use in broader settings. The processes undertaken are likely useful for other professional bodies and standard writers to consider when writing or reviewing their own practice standards, or even guidelines. The researchers suggest that when applying this approach to other documents for use in other contexts that research teams ensure representation from relevant disciplines to aid interpretation and application of the framework.

\section{Strengths and limitations}

To the researchers' knowledge, this is the first study to apply the AACTT framework to evaluate behavioural descriptions in practice standards. As this was not the original purpose of the framework, significant interpretation and adaptation by the research team was required. However, we ensured rigor in the process through the completion of extensive reliability checks throughout the process of developing the codebook and applying it across the dataset. This included discussion until consensus was reached on the sections of the standards reviewed and the definitions in the codebook, after multiple rounds of duplicate pilot coding on sections of the document. After consensus on the codebook was reached and it was applied to all included data, a final $20 \%$ second researcher check on the data was performed. The same two researchers conducted this entire process. One researcher had a professional background as a pharmacist and the second as a behavioural scientist, ensuring both relevant areas of expertise were represented in each reliability check. The results from this study are based on the evaluation of one practice standard, limiting their generalisability. It remains unclear if the lack of specificity is particular to the specific standards evaluated. However, it was deemed necessary to limit the study to one standard, in the first instance, to ensure that adequate detail in the process undertaken could be reported and replicated in future research.

Future work should investigate the extent to which these findings apply to other pharmacist practice standards internationally. Additionally, other health professions may benefit from reviewing their own practice standards and guidelines in this manner. It would also be beneficial to explore end user perceptions of barriers and enablers to using these documents as intended. Once appropriately specified, there are a plethora of tools to support understanding influences on behaviours and matching this to congruent intervention components (e.g. the Behaviour Change Wheel) [20].

\section{Conclusions}

The Professional Practice Standards for Australian Pharmacists do not specify behaviours adequately which risks misinterpretation and a lack of consistency in professional practice. The lack of specificity also limits opportunities to observe and measure the behaviours of the profession and to develop interventions to increase the likelihood that desired professional behaviours are enacted. Behavioural specification frameworks, such as the AACTT framework, can be applied to shed light on the intrinsic characteristics of how specifically behaviours in practice standards are expressed. These results could be used to improve practice standards and guidelines across professions and disciplines in the future.

\section{Appendix}

Table 7 


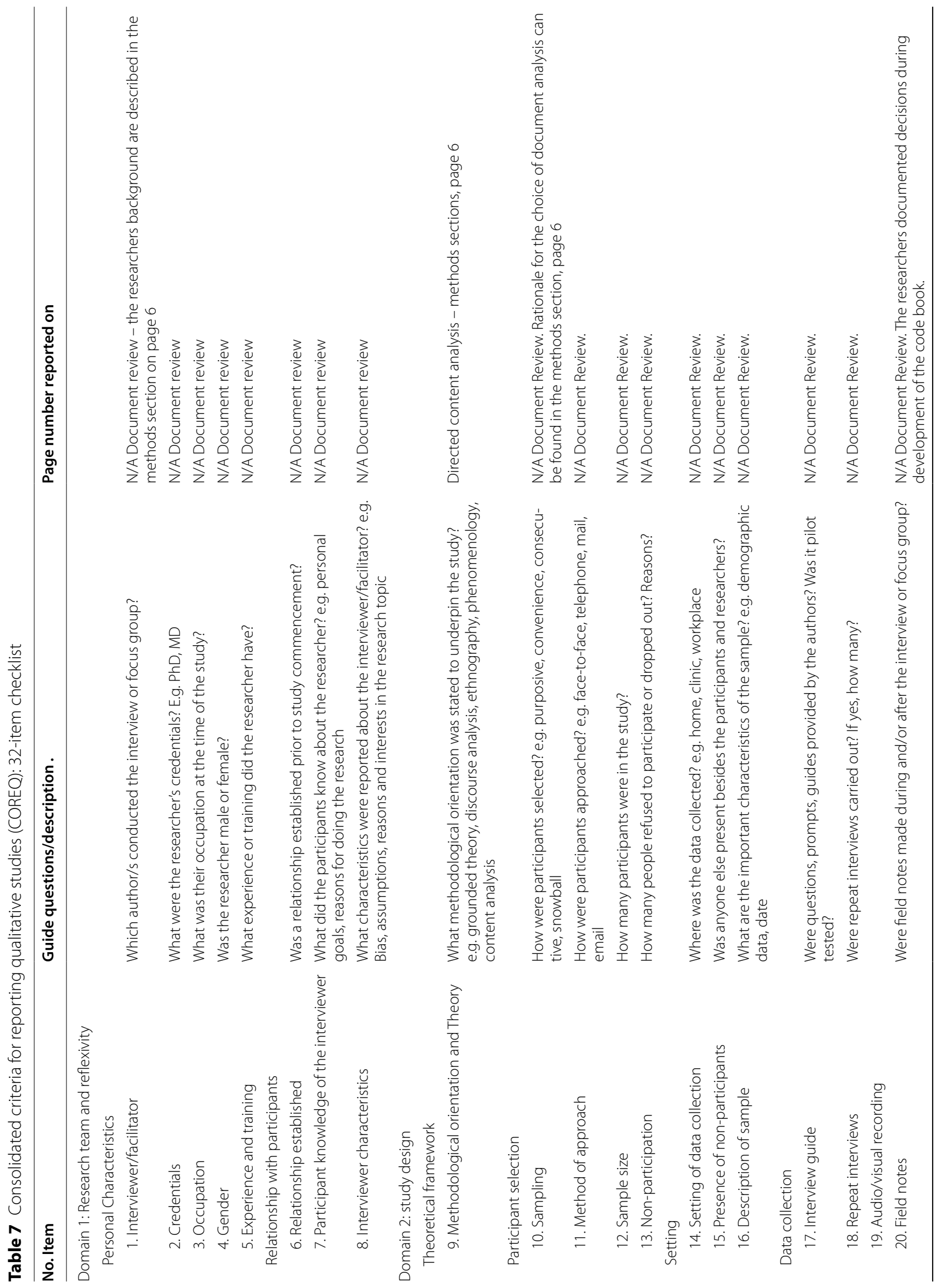




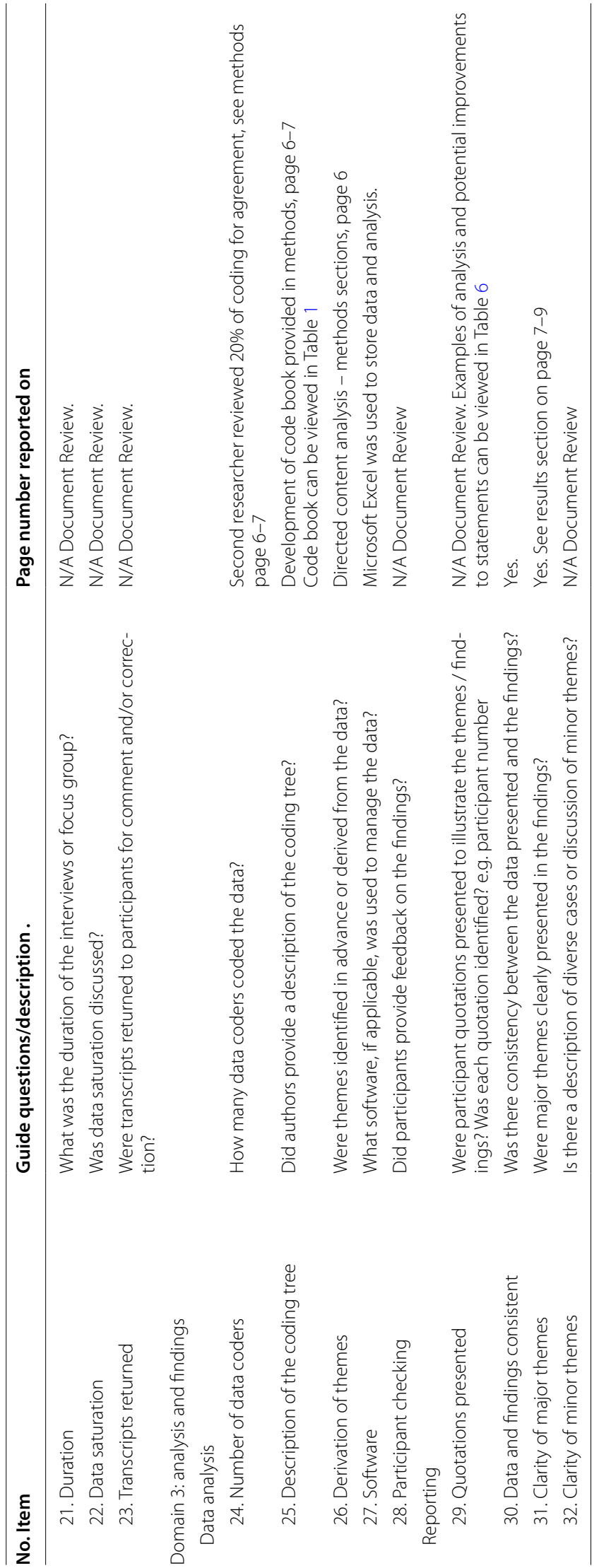




\section{Abbreviations}

AACTT: Actor, Action, Context, Target, Time; TACT-A: Time, Action, Context, Target-Actor; PSA: Pharmaceutical Society of Australia.

\section{Acknowledgements}

The authors would like to thank pharmacy student Puthearothsopor Tan for her assistance with data extraction during the study. DM is supported by an Australian Government Research Training Program Scholarship at The University of Western Australia. AP is supported by an NHMRC Early Career Fellowship (1156892).

\section{Authors' contributions}

The study was conceptualised, and the final manuscript reviewed and edited by DM, DD, RC, SS, JJ, AP, KL and LS. DM led the development of the research question, methodological design, data extraction, analysis and result synthesis under the supervision and with assistance of DD. DM co-ordinated the study, managed all related data and drafted the original manuscript. The authors read and approved the final manuscript.

\section{Funding}

This study was partially funded by the Pharmaceutical Society of Australia (PSA). However, PSA were not involved in the design of the study, data collection, analysis or the writing of this manuscript.

\section{Availability of data and materials}

The datasets used and/or analysed during the current study available from the corresponding author on reasonable request.

\section{Declarations}

\section{Ethics approval and consent to participate}

Not applicable.

\section{Consent for publication}

Not applicable.

\section{Competing interests}

None to declare.

\section{Author details}

'School of Allied Health, The University of Western Australia, Perth, Western Australia, Australia. ${ }^{2}$ Pharmacy Department, The Alfred, Melbourne, Victoria, Australia. ${ }^{3}$ Centre for Medicines Use and Safety, Monash University, Melbourne, Victoria, Australia. ${ }^{4}$ UniSA Clinical and Health Sciences, University of South Australia, Adelaide, South Australia, Australia. ${ }^{5}$ SA Pharmacy, SA Health, Adelaide, South Australia, Australia. ${ }^{6}$ Centre for Behaviour Change, Department of Clinical, Educational and Health Psychology, University College London, London, UK.

Received: 7 August 2021 Accepted: 29 November 2021

Published online: 14 January 2022

\section{References}

1. Institute of Medicine Committee on Quality of Health Care in America, Ed Donaldson MS, Corrigan JM, Kohn LT. To Err Is Human : Building a Safer Health System. Washington, DC: National Academies Press; 2000 [cited 7 July 2021]. Available from: http://ebookcentral.proquest.com/lib/unisa/ detail.action?docID=3375380.

2. Shekelle PG. Clinical practice guidelines: What's next? JAMA. 2018:320(8):757-8.

3. Woolf SH, Grol R, Hutchinson A, Eccles M, Grimshaw J. Clinical guidelines: potential benefits, limitations, and harms of clinical guidelines. BMJ. 1999;318(7182):527-30.

4. International Pharmaceutical Federation. Good Pharmacy Practice- Joint FIP/WHO Guidelines on GPP: Standards for quality of pharmacy services [Internet] 2011, [cited 7 July 2021]. Available from: https://www.fip.org/ file/1476.
5. International Pharmaceutical Federation. FIP Statement of Professional Standards- Code of ethics for pharmacists [Internet]2014, [cited 7 July 2021]. Available from: www.fip.org/statements.

6. Pharmaceutical Society of Australia. Professional practice standards- version 5- June 2017 [internet]. Deakin West ACT Australia: Pharmaceutical Society of South Australia; 2017. Available from: https://www.psa.org.au/ wp-content/uploads/2018/08/Professional-Practice-Standards-v5.pdf

7. World Health Organisation. WHO Guidelines Geneva Switzerland: World Health Organisation; 2021 [cited July 7 2021]. Available from: https:// www.who.int/publications/who-guidelines.

8. Wallen GR, Fisher CA. Chapter 39 - Clinical research nursing: a new domain of practice. In: Principles and practice of clinical research (fourth edition) [internet]. Boston: Academic Press; 2018. p. 671-85. [cited 7 July 2021]; . Available from: https://www.sciencedirect.com/science/article/ pii/B9780128499054000393.

9. Penm J, Chaar BB. Professional transgressions by Australian pharmacists. J Pharm Pract Res. 2009;39(3):192-7.

10. Haggan M. Reprimand after lethal script Aust J Pharm [Internet]. 2021 [cited 2021 July 12]. Available from: https://ajp.com.au/news/repri mand-after-lethal-script/.

11. Grimmer K, Dizon JM, Milanese S, King E, Beaton K, Thorpe O, et al. Efficient clinical evaluation of guideline quality: development and testing of a new tool. BMC Med Res Methodol. 2014;14(1).

12. Grol R, Dalhuijsen J, Thomas S, in 't Veld C, Rutten G, Mokkink H. Attributes of clinical guidelines that influence use of guidelines in general practice: observational study. BMJ. 1998;317:858-64.

13. Gupta S, Rai N, Bhattacharrya O, Cheng AYY, Connelly KA, Boulet L-P, et al. Optimizing the language and format of guidelines to improve guideline uptake. Can Med Assoc J. 2016;188(14):E362-8.

14. Ince $P$, Tai S, Haddock G. Using plain English and behaviourally specific language to increase the implementation of clinical quidelines for psychological treatments in schizophrenia. J Ment Health. 2015;24(3):129-33.

15. Kastner M, Bhattacharyya O, Hayden L, Makarski J, Estey E, Durocher L, et al. Guideline uptake is influenced by six implementability domains for creating and communicating guidelines: a realist review. J Clin Epidemiol. 2015;68(5):498-509.

16. Michie S, Johnston M. Changing clinical behaviour by making guidelines specific. BMJ. 2004;328(7435):343.

17. Shekelle PG, Kravitz RL, Beart J, Marger M, Wang M, Lee M. Are nonspecific practice guidelines potentially harmful? A randomized comparison of the effect of nonspecific versus specific guidelines on physician decision making. Health Serv Res. 2000;34(7):1429-48.

18. Smith D, Sekhon M, Francis JJ, Aitken LM. How actionable are staff behaviours specified in policy documents? A document analysis of protocols for managing deteriorating patients. J Clin Nurs. 2019;28(21-22):4139-49.

19. Michie S, Lester K. Words matter: increasing the implementation of clinical guidelines. Qual Saf Health Care. 2005;14(5):367-70.

20. Michie $S$, Atkins L, West R. The behaviour change wheel: a guide to designing interventions. 1st ed. Great Britain: Silverback Publishing; 2014.

21. Michie S, Van Stralen MM, West R. The behaviour change wheel: a new method for characterising and designing behaviour change interventions. Impl Sci. 2011;6(1).

22. Presseau J, Mutsaers B, Al-Jaishi AA, Squires J, Mclntyre CW, Garg AX, et al. Barriers and facilitators to healthcare professional behaviour change in clinical trials using the theoretical domains framework: a case study of a trial of individualized temperature-reduced haemodialysis. Trials. 2017:18(1):227.

23. Presseau J, McCleary N, Lorencatto F, Patey AM, Grimshaw JM, Francis JJ. Action, actor, context, target, time (AACTT): a framework for specifying behaviour. Implement Sci. 2019;14(1):102.

24. Fishbein M, Ajzen I. Predicting and Changing Behavior : The Reasoned Action Approach. London: Taylor \& Francis Group; 2009. [cited June 2 2021]. Available from: http://ebookcentral.proquest.com/lib/unisa/detail. action?doclD $=668501$

25. Francis JJ, Presseau J. Health Care Practitioner Behaviour. In: Cambridge Handbook of Psychology, Health and Medicine [Internet]. Cambridge: Cambridge University Press; 2019. p. 325-8. [cited June 2 2021]. Available from: https://www.cambridge.org/core/books/cambridge-handbook-ofpsychology-health-and-medicine/health-care-practitioner-behaviour/ 8085E6A2DAA5A497FD9FD6A5CFB4C4A5. 
26. Gould NJ, Lorencatto F, Stanworth SJ, Michie S, Prior ME, Glidewell L, et al. Application of theory to enhance audit and feedback interventions to increase the uptake of evidence-based transfusion practice: an intervention development protocol. Implement Sci. 2014;9(1):92.

27. Smith D, Cartwright M, Dyson J, Hartin J, Aitken LM. Patterns of behaviour in nursing staff actioning the afferent limb of the rapid response system (RRS): a focused ethnography. J Adv Nurs. 2020;76(12):3548-62.

28. Smith D, Francis JJ, Aitken LM. DEveloping a complex intervention for DEteriorating patients using theoretical modelling (DECIDE study): study protocol. J Adv Nurs. 2019;75(9):2024-35.

29. Hsieh H-F, Shannon SE. Three approaches to qualitative content analysis. Qual Health Res. 2005;15(9):1277-88.

30. Bowen GA. Document analysis as a qualitative research method. Qual Res J. 2009;9(2):27-40.

31. Tong A, Sainsbury P, Craig J. Consolidated criteria for reporting qualitative research (COREQ): a 32-item checklist for interviews and focus groups. Int J Qual Health Care. 2007;19(6):349-57.

32. Macquarie Dictionary Online, 2021, Macquarie Dictionary Publishers, an imprint of Pan Macmillan Australia Pty Ltd, cited July 7 2021, accessed via www.macquariedictionary.com.au.

33. Gregory PAM, Austin Z. How do patients develop trust in community pharmacists? Res Soc Adm Pharm. 2021;17(5):911-20.

34. Gregory PAM, Austin Z. Understanding the psychology of trust between patients and their community pharmacists. Canadian Pharm J. 2021;154(2):120-8.

\section{Publisher's Note}

Springer Nature remains neutral with regard to jurisdictional claims in published maps and institutional affiliations.

- fast, convenient online submission

- thorough peer review by experienced researchers in your field

- rapid publication on acceptance

- support for research data, including large and complex data types

- gold Open Access which fosters wider collaboration and increased citations

- maximum visibility for your research: over $100 \mathrm{M}$ website views per year

At BMC, research is always in progress.

Learn more biomedcentral.com/submissions 